Original Article

\title{
The effects of Pilates exercise on cardiopulmonary function in the chronic stroke patients: a randomized controlled trials
}

\author{
Hee Sung Lim, PT, PhD ${ }^{1)}$, Sukhoon Yoon, $\mathrm{PhD}^{2)^{*}}$ \\ 1) Department of Physical Education, Korea National Sport University, Republic of Korea \\ 2) Department of Community Sport, Korea National Sport University: 1239 Yangjaedaero, Songpa-gu, \\ Seoul 138-763, Republic of Korea
}

\begin{abstract}
Purpose] The purpose of this study was to examine the effect of modified Pilates exercise on cardiopulmonary function in chronic stroke patients. [Subjects and Methods] Twenty participants (age, $62.7 \pm 7.3$ years; height, $163.3 \pm 8.5 \mathrm{~cm}$; weight, $68.8 \pm 10.3 \mathrm{~kg}$ ) were recruited for this study, and randomly allocated to the modified Pilates exercise group $(n=10)$ or the control group $(n=10)$. Graded submaximal treadmill exercise test was used to examine the status of patients' cardiopulmonary function, based on maximal oxygen intake, at the end of a patient's exercise tolerance limit. [Results] The resting heart rates, maximal oxygen intake, and maximal oxygen intake per kilogram were significantly different after 8 weeks of modified Pilates exercise. In addition, these variables were also significantly different between the Pilates and control groups after 8 weeks. [Conclusion] This study has demonstrated that 8 weeks of modified Pilates exercise program can have a positive influence on patients with chronic stroke, potentially by enhancing the cardiopulmonary function, which may have positive implications for increasing their functional ability.

Key words: Cardiopulmonary function, Stroke, Pilates exercise
\end{abstract}

(This article was submitted Feb. 20, 2017, and was accepted Mar. 30, 2017)

\section{INTRODUCTION}

One in two stroke survivors have reduced physical activities due to hemiplegia following the onset of stroke ${ }^{1)}$. Reduced respiratory functions due to hemiplegia can lead to reduced endurance, and increased risk of dyspnea and stroke relapse ${ }^{2)}$. Reduced balance and hemiplegia, which characteristically result from stroke, cause the body alignment to become asymmetrical due to the difference between the paralyzed side and non-paralyzed sides. This causes a bias of in the pressure center toward one side, and consequently, always exposes the patient to a risk of fallings ${ }^{3}$. Compensatory movements occur in various parts of the body in hemiplegic patients, causing them to consume more energy than normal persons do. These patients eventually lose physical independence, and experience a reduction in their gait and balance abilities ${ }^{4}$. This eventually leads to reduced physical activity, and subsequently, reduced respiratory function ${ }^{5,6}$. Reduced respiratory functions further compromises physical activity by increasing energy expenditure to account for 55-100\% of the energy consumed during normal walking ${ }^{7)}$. Without sufficient strength to perform physical activities, respiratory functions weaken over time, and the risk of cardiovascular disorders increases in a vicious cycle. Therefore, interventions that promote functional and cardiovascular recoveries must be developed to help patients restore their physical activities ${ }^{8)}$, in addition to physical training that can strengthen their respiratory muscles and improve respiratory functions. Breathing increases one's level of concentration, and relaxes and stretches stiff muscles to increase their lung capacity. Breathing also prepares the body to perform movements in the best condition possible ${ }^{9,10}$. However, most types of exercise do not involve conscious breathing. Pilates is a whole-body

\footnotetext{
*Corresponding author. Sukhoon Yoon (E-mail: sxy134@knsu.ac.kr)

(C)2017 The Society of Physical Therapy Science. Published by IPEC Inc.

This is an open-access article distributed under the terms of the Creative Commons Attribution Non-Commercial No Derivatives (by-nc-nd) License. (CC-BY-NC-ND 4.0: http://creativecommons.org/licenses/by-nc-nd/4.0/)
} 
exercise that involves continuous breathing practice through which a patient can connect his/her spiritual with physical self, and improve his/her body alignment and balance.

Regarding cardiovascular responses during exercise, blood supply should be adequately distributed to exercising muscles to maintain body homeostasis, and heat generated from muscle contraction should be dispersed and adequately supplied to the heart and blood. Respiratory functions can be functionally improved by trainings ${ }^{11}$. Patients with stroke should improve their respiratory functions through high intensity aerobic exercise to prevent and recover from functional loss of respiratory muscles and reduced endurance ${ }^{12-14)}$. Interventions involving exercises such as leg cycle ergometry, treadmill training, and combined upper- and lower-limb ergometry have beneficial cardiovascular effects on patients with acute and chronic stroke ${ }^{15)}$.

However, these interventions focus on improving patients' gait and balance abilities, rather than their respiratory functions ${ }^{16)}$, and the included exercises do not reach the target intensity of $70 \%$ of heart rate reserve (HRR), which is recommended by the American Heart Association to prevent decline in physical functional health of a patient ${ }^{17)}$.

Chang et al. ${ }^{18)}$ have recently reported that robot-assisted gait training significantly improves the maximal oxygen consumption, but has limited intensity settings. In addition, they reported that treadmill gait training improved the abilities of both gas transport in the cardiovascular system and gas exchange by the lungs ${ }^{18)}$. They further demonstrated that this training is expected to positively affect the maximal oxygen consumption, which is a marker of these two factors. Nevertheless, further clinical reports on this training method are needed.

Therefore, the present study sought to investigate the effects of Pilates training on respiration, balance, and gait functions of patients with chronic stroke.

\section{SUBJECTS AND METHODS}

This study targeted 20 stroke patients in a rehabilitation center for the disabled (Table 1). To minimize natural ability to recover, patients who had suffered a stroke more than 2 years previously, had a stroke for the first time, and had no cognitive disorders with more than 24 cores of MMSE (mini mental state examination) - K (Korean), those who could communicate, those who had no apraxia or hemi-neglect, and those who could walk at least for more than 10 minutes were selected. Patients who had a cardiac disorder, uncontrollable high blood pressure and pain, orthopedic problems, such as fracture on the pelvic limb or traumatic damage of peripheral nerves, and a visual impairment, visual field defects, or hearing impairments were excluded. Subjects provided written informed consent after receiving detailed information regarding the requirements and purpose of this study. This study was conducted with approval of the Korea National Sport University.

This study was designed as a randomized, controlled trial. After pretesting, 20 participants were randomized into an experimental group $(n=10)$ and control group $(n=10)$. The randomization process was performed using random allocation software ${ }^{19)}$. The experimental and control groups both participated in conventional stroke rehabilitation program, but only the experimental group participated in Pilates exercise. Conventional stroke rehabilitation consisted of joint mobility, muscle strengthening and walking exercise for 30 minutes once a day, 5 days a week, over 8 weeks.

The exercise group performed Pilates exercise, using a mat that was modified to be suitable for stroke patients. Pilates in these patients involved the use of props such as balls, magic circles and theraband. The exercise group participated in the exercise 24 times. One subject in the control group declined his participation due to health reason. Therefore, test results from the Pilates group and the control group, which each consisted of 10 patients, was used for statistical analysis.

The Pilates exercise was organized based on mat movements, and made stroke patients with hemiparalysis smoothly perform movements using props (i.e. ball, magic circle and theraband). Each session was conducted for an hour, three times a week for 8 weeks. Two certified Pilates instructors and one experienced physical therapist were in charge of the class. One instructor demonstrated movements for patients to follow and the other instructor and a physical therapist assisted and helped patients perform the exercises. All movements of this Pilates exercise were based on 8 sets. To improve core stability, patients started with a breathing exercise in a sitting posture before and after all movements for 10 minutes. A mat based Pilates exercise comprised spine mobility exercises, upper limb exercises and lower limb strengthening exercises. Each part was composed of the following detailed movements. First, spine mobility: chin up and down; spine stretch forward and side with theraband in sitting position. Second, upper limb exercise; draw a sword; deltoid lift in sitting position with theraband. Third, lower limb strengthening exercise: top leg pulse-down and bottom leg pulse-down in side-lying position with magic circle; foot and ankle strengthener in sitting position with theraband. Particularly, unlike general Pilates exercise, lower limb strengthening exercises were designed to help strengthen the quadriceps, gluteus medius, adductor magnus, gastrocnemius, and anterior tibilalis ${ }^{20)}$.

Measurement of cardiac functional capacity was performed using a graded submaximal treadmill exercise test to estimate the best state of subjects' cardiopulmonary function, using maximal oxygen intake, after finishing exercise before a subject reaches maximum exercise. In this study the test was conducted using treadmill and radio wire metabolic analyzer (Quark b2, COSMED, Italy, 2011), after resting heart rate and target heart rate were measured before the test. A radio wire metabolic analyzer measures and assesses maximal aerobic capacity while walking on treadmill. The slope of treadmill was set $0^{\circ}$. The target walking velocity was selected for patient's walking stability and continuous treadmill test ${ }^{21)}$. Subjects were asked to use a minimal level of handrail support. In addition, the subjects were asked to wear a belt around their waists to provide security during testing, and to use shoes or aids. Moreover, when they expressed difficulty while walking, they were offered modest amounts of help. The cardiopulmonary function test was conducted using the Harbor protocol, which is applicable to patients 
Table 1. General characteristics of subjects $(n=20)$

\begin{tabular}{lcc}
\hline & PG $(\mathrm{n}=10)$ & $\mathrm{CG}(\mathrm{n}=10)$ \\
\hline Gender & 6 males/4 females & 5 males/5 females \\
Age (years) & $63.2(7.9)$ & $62.1(6.7)$ \\
Body mass $(\mathrm{kg})$ & $69.5(10.4)$ & $68.0(10.1)$ \\
Height $(\mathrm{cm})$ & $161.6(7.7)$ & $164.9(9.2)$ \\
\hline
\end{tabular}

PG: Pilates exercise group; CG: Control group

Values are group means (standard deviation).
Table 3. The changes of TUG between exercise periods $(n=20)$

\begin{tabular}{lcc}
\hline & PG $(\mathrm{n}=10)$ & $\mathrm{CG}(\mathrm{n}=10)$ \\
\hline TUG $(\mathrm{s})$ & & \\
Pre & $-22.6 \pm 5.7$ & $19.2 \pm 5.4$ \\
Post & $-19.2 \pm 5.8^{*}$ & $21.7 \pm 6.4^{*}$ \\
Pre-Post & $-3.5 \pm 4.7$ & $2.5 \pm 1.2$ \\
\hline
\end{tabular}

PG: Pilates exercise group; CG: Control group; TUG: Time up and go. Values are expressed as group mean \pm standard error. *Significant difference between pre- and post- intervention $(\mathrm{p}<0.05)$

Table 2. The changes of cardiopulmonary function between exercise periods $(\mathrm{n}=20)$

\begin{tabular}{lcc}
\hline & PG $(\mathrm{n}=10)$ & $\mathrm{CG}(\mathrm{n}=10)$ \\
\hline Resting heart rate $(\mathrm{bpm})$ & & \\
Pre & $84.10 \pm 16.6$ & $83.3 \pm 17.3$ \\
Post & $76.50 \pm 14.5^{*}$ & $85.4 \pm 16.6^{*}$ \\
Pre-Post & $-7.60 \pm 4.9$ & $2.11 \pm 1.83$ \\
$\mathrm{VO}_{2} \max (\mathrm{ml} / \mathrm{min})$ & & \\
Pre & $819.3 \pm 251.4$ & $1,048.8 \pm 420.5$ \\
Post & $964.8 \pm 244.2^{*}$ & $1,027.3 \pm 416.5^{*}$ \\
Pre-Post & $145.5 \pm 85.7$ & $-21.4 \pm 18.4$ \\
$\mathrm{VO}_{2}$ max per $\mathrm{kg}(\mathrm{ml} / \mathrm{kg} / \mathrm{min})$ & & \\
Pre & $12.1 \pm 2.9$ & $14.7 \pm 4.7$ \\
Post & $14.3 \pm 2.5^{*}$ & $14.4 \pm 4.7^{*}$ \\
Pre-Post & $2.3 \pm 1.6$ & $-0.3 \pm 0.3$ \\
\hline
\end{tabular}

PG: Pilates exercise group; CG: Control group; $\mathrm{VO}_{2}$ max: Maximal oxygen intake. Values are expressed as group mean \pm standard error. *Significant difference between pre- and post- intervention $(\mathrm{p}<0.05)$

with weakened physical function, such as the elderly or hemiplegic patients. The transformed Harbor protocol tested treadmill velocity starts with the usual walking speed, for 10 minutes by increasing $0.09 \mathrm{~m} / \mathrm{s}(0.2 \mathrm{mph})$ every 2 minutes. The test was conducted until it reached $80 \%$ of the aged-predicted maximum heart rate of each subject ${ }^{5,21)}$. Subjects were instructed to use maximal effort and to display the thumb-down signal when they wished to terminate the test. Termination of testing followed ACSM guidelines ${ }^{12,22)}$. The graded submaximal treadmill exercise test was used to assess the maximal oxygen intake $\left(\mathrm{VO}_{2}\right.$ max) and maximal oxygen intake per body weight. The Time Up and Go test (TUG) was used as a test of dynamic gait ability and balance, which is commonly used to examine functional mobility of chronic stroke patients in this study.

Data were analyzed using SPSS for Window Version 18.0. A paired t-test was used to compare the pretest and posttest subordinate variables in each group. An independent t-test was used to compare the differences in subordinate variables between the Pilates and control group. All statistical significance level $(\alpha)$ of all statistical materials were set at 0.05 .

\section{RESULTS}

Cardiopulmonary function, as indicated by resting heart rates, $\mathrm{VO}_{2}$ max, and $\mathrm{VO}_{2}$ max per kg, were significantly different after 8 weeks of intervention (Table 2, $\mathrm{p}<0.05$ ). Furthermore, the control group also displayed significant differences in these variables following intervention (Table 2, $\mathrm{p}<0.05$ ). Resting heart rate, $\mathrm{VO}_{2}$ max, and $\mathrm{VO}_{2}$ max per $\mathrm{kg}$ were significantly different between the Pilates and control groups after 8 weeks of Pilates exercise (Table 2, $\mathrm{p}<0.05$ ).

In the TUG test, the Pilates group displayed significant improvements after 8 weeks of intervention (Table $3, \mathrm{p}<0.05$ ). Significant differences were found in the control group between before and after the exercise (Table $3, p<0.05$ ). In addition, results of the TUG test were significantly different between the Pilates and control group (Table 3, p<0.05).

\section{DISCUSSION}

Stroke patients can experience paralysis in their limbs due to motor function disorder and sensory dysfunction, thereby seriously restricting physical activity ${ }^{23}$. Therefore, stroke patients, owing to a reduction in physical activity, show muscular weakness, balance reduction and hypokinesia, a decline in body metabolic function; and a reduction in cardiopulmonary 
function by $50-70 \%$, compared to healthy people ${ }^{24,25}$. It has been reported that chronic stroke patients can develop accompanying respiratory deficits over time, due to restrictions in physical activity and a decline in movement ${ }^{26}$. Respiratory function weakness causes a vicious cycle that restricts physical activity, thereby further aggravating respiratory function ${ }^{27)}$. Therefore, reduction in respiratory function is an important problem to overcome in stroke patients. Accordingly, a reduction in cardiopulmonary capacity of various damaged parts of the chronic stroke patients occupies a large part of the physical disabilities and works as an important element with reduction of ambulation ability, when they return to the communities after the nervous system rehabilitation treatment ${ }^{8,28)}$. Therefore, this study tried to determine the degree of the cardiopulmonary function, by measuring resting heart rate, maximal oxygen intake and maximal oxygen intake per body weight, targeting chronic stroke patients, to assess if the continuous Pilates exercise was of help to the increase in their cardiopulmonary capacity, which takes an important part when they return to their daily lives.

The resting heart rate is the heart rates under stable conditions; which inversely is related to exercise tolerance. If physical strength improves, the resting heart rate decreases. Therefore, the heart rate recovers more quickly after exercise. Measurements of resting heart rate, as conducted in this study, showed a statistically significant reduction after training in the Pilates, while the resting heart rate increased statistically significantly in control group (Table 2, $\mathrm{p}<0.05$ ).

The maximal oxygen intake is defined as the maximum amount of oxygen that can be consumed per minute during maximum exercise. It is a value obtained by direct measurement; and is a primary indicator that assesses absolute capacity of the cardiopulmonary system ${ }^{29}$ ). In addition, when the maximal oxygen intake is assessed, maximal oxygen intake per body weight is used for relative evaluation, which is reported to show the most suitable cardiopulmonary capacity when a trained person and an untrained person are compare ${ }^{30)}$. Oxygen is necessary for contraction and relaxation of skeletal muscles mobilized during long exercise. The whole body including breathing, circulation, nervous system activity, and muscles uses this oxygen. Therefore, a higher oxygen intake, indicates an improved ability to perform intensive exercise within a given time ${ }^{30)}$.

Huang et al. ${ }^{31)}$ reported that continuous moderate exercise of more than 3 days per week improves maximal oxygen intake by $35-50 \%$ and differences in $\mathrm{VO}_{2}$ max changes were significantly related to exercise intensity, which accounts for the approximately $11 \%$ variance in $\mathrm{VO}_{2}$ max responses. A study on the maximal oxygen intake related to the cardiovascular system of the stroke patients showed that a higher Barthel index according to independence in daily life correlates to more oxygen intake ${ }^{6}$. Kelley et al. ${ }^{32)}$ reported that the level of subacute stroke patients' maximal oxygen intake, gait velocity and endurance was just $50 \%$ of a normal person.

This study showed that Pilate's group maximal oxygen intake increased significantly from $819.4 \mathrm{ml} / \mathrm{min}$ before exercise to $964.8 \mathrm{ml} / \mathrm{min}$ after exercise, while control group's maximal oxygen intake was significantly reduced before and after exercise from $1,048.78 \mathrm{ml} / \mathrm{min}$ to $1,027.33 \mathrm{ml} / \mathrm{min}$ (Table 3, $\mathrm{p}<0.05$ ). In addition, Pilate's group maximal oxygen intake per body weight statistically significantly increased from $12.06 \mathrm{ml} / \mathrm{kg} / \mathrm{min}$ before exercise to $14.31 \mathrm{ml} / \mathrm{kg} / \mathrm{min}$ after exercise, while the control group experienced a statistically significantly reduction from before to after exercise $14.68 \mathrm{ml} / \mathrm{kg} / \mathrm{min}$ to $14.38 \mathrm{ml} /$ $\mathrm{kg} / \mathrm{min}$ (Table 3, $\mathrm{p}<0.05$ ).

The results of this study are similar to the results of a 16-week Pilates exercise that Guimarães et al. ${ }^{33)}$ conducted in 16 patients with heart failure; Guimarães et al. ${ }^{33)}$ said that these changes meant an increase in stroke volume, arteriovenous oxygen difference, or an improvement in muscular metabolic adaptation related to the former two.

In addition, we believe that the results of this study are due to that the maintenance of motor unit recruitment and of muscle mass in patients through regular aerobic exercise, such as Pilates ${ }^{34)}$. Alternatively, the mobilization of additional motor units after exercise maintains oxygen consumption ability by maintaining the number of active mitochondria ${ }^{35)}$. Breathing is central to Pilates exercise. Therefore, if breathing is ceased, muscles become strained and insufficient postures are aggravated. The muscles that are associated with breathing, such as the diaphragm, transversus abdominis, pelvic floor muscles, multifidus muscles, intercostal muscles, serratus anterior, scalenus and upper trapezius muscle, become strained. Therefore, breathing improves lung capacity and concentration, and elevates strengthening and movability of muscles during exercise, that we can perform movements easily ${ }^{36)}$.

In this study, a Tug test was performed to assess the gait and balance abilities. The results of this study are consistent with previous studies, which reported that improvements in respiratory functions affected mobility.

Therefore, it is believed that, as Pilates regimen includes breathing exercise, it contributes to a reduction in kinetic energy necessary to experience an increase in ventilation efficiency and movement. As the Pilates exercise showed a positive effect on improvement in cardiopulmonary function and a possible therapeutic role, more studies should be conducted in the future to assess the effects of Pilates on long-term improvements in cardiopulmonary function.

\section{REFERENCES}

1) Jørgensen HS, Nakayama H, Raaschou HO, et al.: Recovery of walking function in stroke patients: the Copenhagen Stroke Study. Arch Phys Med Rehabil, 1995, 76: 27-32. [Medline] [CrossRef]

2) Joo S, Shin D, Song C: The effects of game-based breathing exercise on pulmonary function in stroke patients: a preliminary study. Med Sci Monit, 2015, 21: 1806-1811. [Medline] [CrossRef]

3) Laufer Y, Dickstein R, Resnik S, et al.: Weight-bearing shifts of hemiparetic and healthy adults upon stepping on stairs of various heights. Clin Rehabil, 2000, 
14: 125-129. [Medline] [CrossRef]

4) Michael KM, Allen JK, Macko RF: Reduced ambulatory activity after stroke: the role of balance, gait, and cardiovascular fitness. Arch Phys Med Rehabil, 2005, 86: 1552-1556. [Medline] [CrossRef]

5) Dobrovolny CL, Ivey FM, Rogers MA, et al.: Reliability of treadmill exercise testing in older patients with chronic hemiparetic stroke. Arch Phys Med Rehabil, 2003, 84: 1308-1312. [Medline] [CrossRef]

6) Mackay-Lyons MJ, Makrides L: Longitudinal changes in exercise capacity after stroke. Arch Phys Med Rehabil, 2004, 85: 1608-1612. [Medline] [CrossRef]

7) Hooker SP, Sui X, Colabianchi N, et al.: Cardiorespiratory fitness as a predictor of fatal and nonfatal stroke in asymptomatic women and men. Stroke, 2008, 39: 2950-2957. [Medline] [CrossRef]

8) Hermann DM, Bassetti CL: Sleep-related breathing and sleep-wake disturbances in ischemic stroke. Neurology, 2009, 73: 1313-1322. [Medline] [CrossRef]

9) Skinner JS: Exercise testing \& exercise prescription for special cases: theoretical basis \& clinical application, 3rd ed. Philadelphia: Lippincott Williams \& Wilkins, 2005, pp 318-321.

10) Kim BJ, Bae SS, Hwangbo G: The improve of hemiplegic patients functional ambulation profile by forceful respiratory exercise. J Kor Soc Phys Ther, 2004, 16: $32-48$.

11) Stuart M, Chard S, Benvenuti F, et al.: Community exercise: a vital component to healthy aging. Healthc Pap, 2009, 10: 23-28, discussion 79-83. [Medline] [CrossRef]

12) Tang A, Sibley KM, Thomas SG, et al.: Maximal exercise test results in subacute stroke. Arch Phys Med Rehabil, 2006, 87: 1100-1105. [Medline] [CrossRef]

13) Teixeira-Salmela LF, Olney SJ, Nadeau S, et al.: Muscle strengthening and physical conditioning to reduce impairment and disability in chronic stroke survivors. Arch Phys Med Rehabil, 1999, 80: 1211-1218. [Medline] [CrossRef]

14) Sezer N, Ordu NK, Sutbeyaz ST, et al.: Cardiopulmonary and metabolic responses to maximum exercise and aerobic capacity in hemiplegic patients. Funct Neurol, 2004, 19: 233-238. [Medline]

15) Stoller O, de Bruin ED, Schindelholz M, et al.: Efficacy of feedback-controlled robotics-assisted treadmill exercise to improve cardiovascular fitness early after stroke: a randomized controlled pilot trial. J Neurol Phys Ther, 2015, 39: 156-165. [Medline] [CrossRef]

16) Kuys S, Brauer S, Ada L: Routine physiotherapy does not induce a cardiorespiratory training effect post-stroke, regardless of walking ability. Physiother Res Int, 2006, 11: 219-227. [Medline] [CrossRef]

17) Gordon NF, Gulanick M, Costa F, et al. American Heart Association Council on Clinical Cardiology, Subcommittee on Exercise, Cardiac Rehabilitation, and Prevention; the Council on Cardiovascular Nursing; the Council on Nutrition, Physical Activity, and Metabolism; and the Stroke Council: Physical activity and exercise recommendations for stroke survivors: an American Heart Association scientific statement from the Council on Clinical Cardiology, Subcommittee on Exercise, Cardiac Rehabilitation, and Prevention; the Council on Cardiovascular Nursing; the Council on Nutrition, Physical Activity, and Metabolism; and the Stroke Council. Circulation, 2004, 109: 2031-2041. [Medline] [CrossRef]

18) Chang WH, Kim MS, Huh JP, et al.: Effects of robot-assisted gait training on cardiopulmonary fitness in subacute stroke patients: a randomized controlled study. Neurorehabil Neural Repair, 2012, 26: 318-324. [Medline] [CrossRef]

19) Saghaei M: Random allocation software for parallel group randomized trials. BMC Med Res Methodol, 2004, 4: 26. [Medline] [CrossRef]

20) Lim HS, Kim YL, Lee SM: The effects of Pilates exercise training on static and dynamic balance in chronic stroke patients: a randomized controlled trial. J Phys Ther Sci, 2016, 28: 1819-1824. [Medline] [CrossRef]

21) Macko RF, Katzel LI, Yataco A, et al.: Low-velocity graded treadmill stress testing in hemiparetic stroke patients. Stroke, 1997, 28: 988-992. [Medline] [CrossRef]

22) Lea F: ACSM's guidelines for exercise testing and prescription. American College of Sports Medicine, Philadelphia, 1995.

23) Kolb B, Gibb R: Brain plasticity and recovery from early cortical injury. Dev Psychobiol, 2007, 49: 107-118. [Medline] [CrossRef]

24) Polese JC, Pinheiro MB, Faria CD, et al.: Strength of the respiratory and lower limb muscles and functional capacity in chronic stroke survivors with different physical activity levels. Braz J Phys Ther, 2013, 17: 487-493. [Medline] [CrossRef]

25) Eng JJ, Dawson AS, Chu KS: Submaximal exercise in persons with stroke: test-retest reliability and concurrent validity with maximal oxygen consumption. Arch Phys Med Rehabil, 2004, 85: 113-118. [Medline] [CrossRef]

26) Estenne M, Knoop C, Vanvaerenbergh J: The effect of pectoralis muscle training in tetraplegic subjects 1-3. 1989.

27) Agnarsson U, Thorgeirsson G, Sigvaldason H, et al.: Effects of leisure-time physical activity and ventilatory function on risk for stroke in men: the Reykjavík Study. Ann Intern Med, 1999, 130: 987-990. [Medline] [CrossRef]

28) Goldie PA, Matyas TA, Evans OM: Deficit and change in gait velocity during rehabilitation after stroke. Arch Phys Med Rehabil, 1996, 77: 1074-1082. [Medline] [CrossRef]

29) Alexander S: Physiologic and biochemical effects of exercise. Clin Biochem, 1984, 17: 126-131. [Medline] [CrossRef]

30) Bruce RA, Li YB, Dower GE, et al.: Polarcardiographic responses to maximal exercise and to changes in posture in healthy middle-aged men. J Electrocardiol, 1973, 6: 91-96. [Medline] [CrossRef]

31) Huang G, Wang R, Chen P, et al.: Dose-response relationship of cardiorespiratory fitness adaptation to controlled endurance training in sedentary older adults. Eur J Prev Cardiol, 2016, 23: 518-529. [Medline] [CrossRef]

32) Kelley CP, Childress J, Boake C, et al.: Over-ground and robotic-assisted locomotor training in adults with chronic stroke: a blinded randomized clinical trial. Disabil Rehabil Assist Technol, 2013, 8: 161-168. [Medline] [CrossRef]

33) Guimarães GV, Carvalho VO, Bocchi EA, et al.: Pilates in heart failure patients: a randomized controlled pilot trial. Cardiovasc Ther, 2012 , 30: 351-356. [Medline] [CrossRef]

34) Thompson PD: The cardiovascular complications of vigorous physical activity. Arch Intern Med, 1996, 156: 2297-2302. [Medline] [CrossRef]

35) Häkkinen K, Alén M, Komi PV: Changes in isometric force- and relaxation-time, electromyographic and muscle fibre characteristics of human skeletal muscle during strength training and detraining. Acta Physiol Scand, 1985, 125: 573-585. [Medline] [CrossRef]

36) Noh SY, Park SM, Bae KJ, et al.: Pilates mat exercise of Elly Herman. 2007: Seoul: Daehan media. 